\title{
Uveitis, vitreous humour, and klebsiella. II. Cross-reactivity studies with radioimmunoassay
}

\author{
J. WELSH, H. AVAKIAN, AND A. EBRINGER \\ From the Immunology Urit, Department of Biochemistry, Queen Elizabeth College, London W8, and the \\ Department of Rheumatology, Middlesex Hospital, London WI
}

SUMMARY Radioimmunoassay with calf and cow vitreous humour-125I and rabbit antivitreous humour serum has been employed to investigate the immunological cross-reactivity of vitreous humour with bacterial and mammalian tissue antigens. Klebsiella ultrasonicate preparation at a dose of $10000 \mu \mathrm{g} / \mathrm{ml}$ was found to inhibit the binding of vitreous humour by $25-100 \%(\mathrm{p}<0.001)$, compared with an inhibition of $5-30 \%$ by a similar quantity of $E$. coli ultrasonicate preparation. Equivalent amounts of Streptococcus pyogenes antigen, bovine haemoglobin, and hyaluronic acid had no inhibitory effect, while horse spleen ferritin was found to inhibit vitreous humour binding between 0 and $10 \%$. These results indicate that klebsiella micro-organisms have antigens which partially resemble some eyeball components. It is suggested that acute anterior uveitis of ankylosing spondylitis may be produced by anti-Gram-negative bacterial antibodies binding to cross-reacting eye antigens.

Acute anterior uveitis (AAU) or iridocyclitis is an inflammatory condition of the uveal tract which may occur in association with a number of arthritic disorders including ankylosing spondylitis (AS), Reiter's syndrome, and Still's disease. The reason for this association is unknown. However, an increased frequency of the histocompatibility allele HLA B27 has been found in these diseases. ${ }^{1-3}$ Klebsiella pneumoniae has been isolated from faecal cultures of patients with active $\mathrm{AS}^{4}$ as well as from $\mathrm{AS}$ patients with uveitis. ${ }^{56} \mathrm{~K}$. pneumoniae has been found to partially cross-react with antigenic determinants located on HLA B27 lymphocytes, ${ }^{78}$ and some of these could involve the HLA B27 antigen itself, ${ }^{9}$ or a closely associated gene product. ${ }^{10}$

In an endeavour to determine a possible pathological connection between Gram-negative microorganisms and uveitis the structural properties of klebsiella miro-organisms have been investigated by competitive inhibition in a vitreous humour radioimmunoassay with bacterial and mammalian tissue antigen extracts.

\section{Materials and methods}

PREPARATION OF VITREOUS HUMOUR ANTISERUM

A New Zealand white rabbit was immunised with crude cow-vitreous-humour $(\mathrm{CVH})$ in incomplete

Correspondence to $\mathrm{Dr} A$. Ebringer, Immunology Unit Department of Biochemistry, Queen Elizabeth College, London W8 7AH.
Freund's adjuvant several times over a period of 6 months as described in the previous paper. ${ }^{11}$ After 9 immunisations the rabbit was bled, the serum was separated and precipitated with half saturated ammonium sulphate, and dialysed against phosphate buffered saline (PBS), and the resulting antibovine vitreous humour immunoglobulin (anti-VH-Ig) preparation (A1) was stored at $-15^{\circ} \mathrm{C}$ until use. A2 immunoglobulin preparation was obtained after 11 immunisations. Preparations were restored to original volume with PBS.

PREPARATION OF BACTERIAL ANTIGENS Klebsiella pneumoniae (MX100) was isolated from a faecal culture of an ankylosing spondylitis patient and the bacterial extract ' $\mathrm{klebsiella}$ sonicate preparation' (KSP) was obtained as previously described. ${ }^{9}$ Briefly, klebsiella micro-organisms were grown on MacConkey culture plates, harvested, washed twice with cold PBS $\left(4^{\circ} \mathrm{C}\right)$, resuspended $\left(20 \mathrm{ml} ; 1.3 \times 10^{13}\right.$ micro-organisms), ultrasonicated, and centrifuged. Supernatant was filtered through Sephadex G25, dialysed against distilled water, and lyophilised. $100 \mathrm{mg}$ residues were recovered which dissolved readily in PBS and $\mathrm{E}_{1} \% \mathrm{~cm}$ at $280 \mathrm{~nm}$ was $11 \cdot 8$. A similar bacterial extract was prepared from Escherichia coli (ML 30) micro-organisms, and streptococcus group A antigen was obtained commercially (Difco).

MAMMALIAN TISSUE ANTIGENS

Mammalian tissue antigens used as controls in the comparative studies were (i) hyaluronic acid prepared 
from human umbilical cord (British Drug Houses); (ii) haemoglobin obtained from beef blood (Sigma); (iii) ferritin extracted from horse spleen (Miles Laboratories).

PREPARATION OF VITREOUS HUMOUR

Bovine vitreous humour was homogenised in a Potter-Elvejhem homogeniser and centrifuged to remove any large particulate matter. The vitreous humour was then ultrasonicated in an MSE 25 ultrasonicator, at medium setting, with 10-second bursts for 4 cycles, recentrifuged, and supernatant dialysed continuously against 10 litres of deionised water before being lyophilised. Calf vitreous humour obtained from younger animals was treated in a similar manner, but, after ultrasonication, the $\mathrm{CVH}$ was centrifuged in an MSE 18 centrifuge for 1 hour at $12000 \mathrm{rpm}$ at $4^{\circ} \mathrm{C}$ and then dialysed overnight at $4^{\circ} \mathrm{C}$ against 10 litres of PBS containing $0 \cdot 1 \%$ sodium azide (PBS-A). The CVH was then desalted on fine Sephadex G25 (Pharmacia) before being lyophilised.

\section{IODINATION AND FRACTIONATION OF \\ VITREOUS HUMOUR}

Crude bovine vitreous humour (CVH) $(2 \mathrm{mg})$ was radiolabelled with $1 \mathrm{mCi}$ of $\mathrm{Na}^{125} \mathrm{I}$ (Radiochemical Centre, Amersham) as described in the previous paper. ${ }^{11}$ After dialysis the ${ }^{125}$ I-labelled vitreous humour was applied to a Sepharose 6B column (Pharmacia), equilibrated with $0 \cdot 15$ M PBS, pH 7·2, containing sodium azide (PBS-A), and the first fraction was collected as described, ${ }^{11}$ stored at $4^{\circ} \mathrm{C}$, and used in subsequent assays.

\section{RADIOBINDING ASSAY}

The assay buffer used in all experiments was $0 \cdot 15 \mathrm{M}$ PBS-A containing $0.4 \%$ bovine serum albumin (BSA) (Radioimmunoassay grade, Sigma). To $50 \mu \mathrm{l}$ assay buffer in an LP3 tube (Luckhams) was added $50 \mu \mathrm{l}$ of tracer CVH-125I followed by $50 \mu \mathrm{l}$ of rabbit anti-VH-Ig in serial dilutions. After 30 minutes' incubation at $37^{\circ} \mathrm{C}, 50 \mu \mathrm{l}$ of coprecipitating donkey antirabbit immunoglobulin $G$ serum (Wellcome Reagents) was added. The optimum dilution of second antibody was determined by measuring the quantity of first antibody precipitated by varying dilutions of coprecipitating antibody. Maximum precipitation was obtained with a dilution of $1 / 180$ of coprecipitating donkey antirabbit IgG serum per $10 \mu \mathrm{g}$ of anti-VH-Ig. The tubes were then left overnight at $4^{\circ} \mathrm{C}$, washed twice with PBS-A containing $0.01 \mathrm{M}$ potassium iodide, centrifuged at $3000 \mathrm{rpm}$ for 30 minutes, and the radioactivity in the precipitate counted in a well-type gamma counter (Packard Model 578). Each serum dilution assay was carried out in quadruplicate and percentage bound $(\% \mathrm{~B})$ was expressed as:

Percentage bound $=\% B=\left[\frac{\text { Test }(\mathrm{cpm})-\text { Blank }(\mathrm{cpm})}{\text { Total }(\mathrm{cpm})-\mathrm{Blank}(\mathrm{cpm})}\right] \times 100$.

SELECTION OF ANTISERUM DILUTION FOR

RADIOIMMUNOASSAY

The dilution of antiserum that binds a given percentage of labelled antigen for use in the radioimmunoassay (RIA) was selected from binding curves, described in the previous paper, ${ }^{11}$ and was taken as the dilution giving maximum difference in percentage bound of $\mathrm{CVH}^{-125} \mathrm{I}$, when comparing antivitreous humour serum with preimmunisation serum from the same rabbit. For instance, for a particular batch of vitreous humour, at a dilution of 1/2000 of anti- VHIg there was $30 \%$ binding of $\mathrm{CVH}^{-125}$ I compared with less than $1 \%$ binding by preimmunisation serum immunoglobulin, and therefore in this particular assay system percentage bound in absence of competitor $\left(\mathrm{B}_{0}\right)$ equals $30 \%$ (Fig. 1). For each new batch of labelled vitreous humour a radiobinding assay was carried out to determine the dilution point of maximum difference in binding between pre- and postimmunisation sera preparations for use in RIA.

\section{RADIOIMMUNOASSAY}

In the radioimmunoassay the concentrations of antibody and radiolabelled tracer remain constant, and increasing amounts of competitor are added to displace the label. A standard competition or inhibition curve is obtained with unlabelled $\mathrm{CVH}$ and compared with inhibition produced by equal quantities of other antigens. To $50 \mu \mathrm{l}$ aliquots of $\mathrm{CVH}^{-125} \mathrm{I}$, diluted as for radiobinding assay, was added $50 \mu \mathrm{l}$ of buffer containing increasing concentrations of competitor, then $50 \mu \mathrm{l}$ of anti-VH-Ig at the dilution determined by the radiobinding assay and incubated at $37^{\circ} \mathrm{C}$ for 30 minutes. After cooling, $50 \mu l$ of coprecipitating serum was added, and the tubes were left overnight at $4^{\circ} \mathrm{C}$. The washing procedure was carried out as for the radiobinding assay, radioactivity counted in a gamma counter, and residual binding with $(\% \mathrm{~B})$ and without competitor $\left(\% \mathbf{B}_{0}\right)$ determined as before. Percentage inhibition $(\% \mathrm{I})$ was calculated as follows:

Percentage inhibition $=\% \mathbf{I}=\left(1-\frac{\mathbf{B}}{\mathbf{B}_{0}}\right) \times 100$.

\section{Results}

CALF VITREOUS HUMOUR

RADIOIMMUNOASSAY

The antiserum dilutions showing maximal binding 


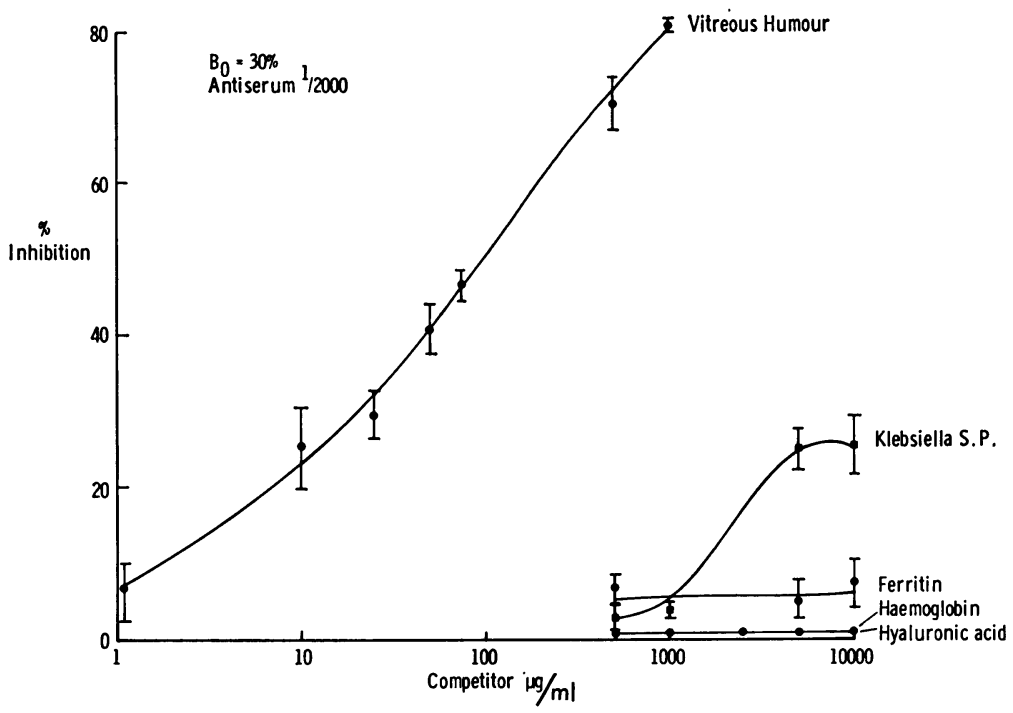

Fig. 1 Inhibition of calf $\mathrm{CVH}-{ }^{125}$ I tracer binding to rabbit anti-VH-Ig, at a dilution of 1/2000, by increasing amounts $(\mu \mathrm{g} / \mathrm{ml})$ of unlabelled vitreous humour, klebsiella sonicate preparation (KSP), ferritin, bovine haemoglobin, and hyaluronic acid. Bars represent means \pm standard errors.

were selected for inhibition studies and were obtained from radiobinding curves prepared for each batch of radiolabelled vitreous humour. RIA studies, with 2 dilutions being used at $1 / 2000$ $\left(B_{0}=30 \%\right)$ and $1 / 840\left(B_{0}=54 \%\right)$ respectively, of $A 2$ preparations of rabbit anti-VH-Ig with calf- ${ }^{125} \mathrm{I}$ are shown in Figs. 1 and 2.

At $10000 \mu \mathrm{g} / \mathrm{ml}$ of competitor, klebsiella extract (KSP) showed $26 \%$ (Fig. 1) and $30 \%$ (Fig. 2) inhibition of vitreous humour binding respectively, while ferritin inhibited less than $10 \%$ and bovine haemoglobin, hyaluronic acid, and streptococcus antigen had no inhibitory effect. The difference in inhibition between KSP and ferritin, when $B_{0}$ equals $54 \%$ (Fig. 2) is statistically significant $(t=20.56$, $\mathrm{p}<0.001)$. Lower concentrations of competitor produced correspondingly lower levels of inhibition.

\section{COW VITREOUS HUMOUR}

RADIOIMMUNOASSAY

RIA studies with rabbit anti-VH-Ig preparations, obtained from 2 separate bleeds (A2 and A1), binding to cow vitreous humour are shown in Figs. 3 and 4.

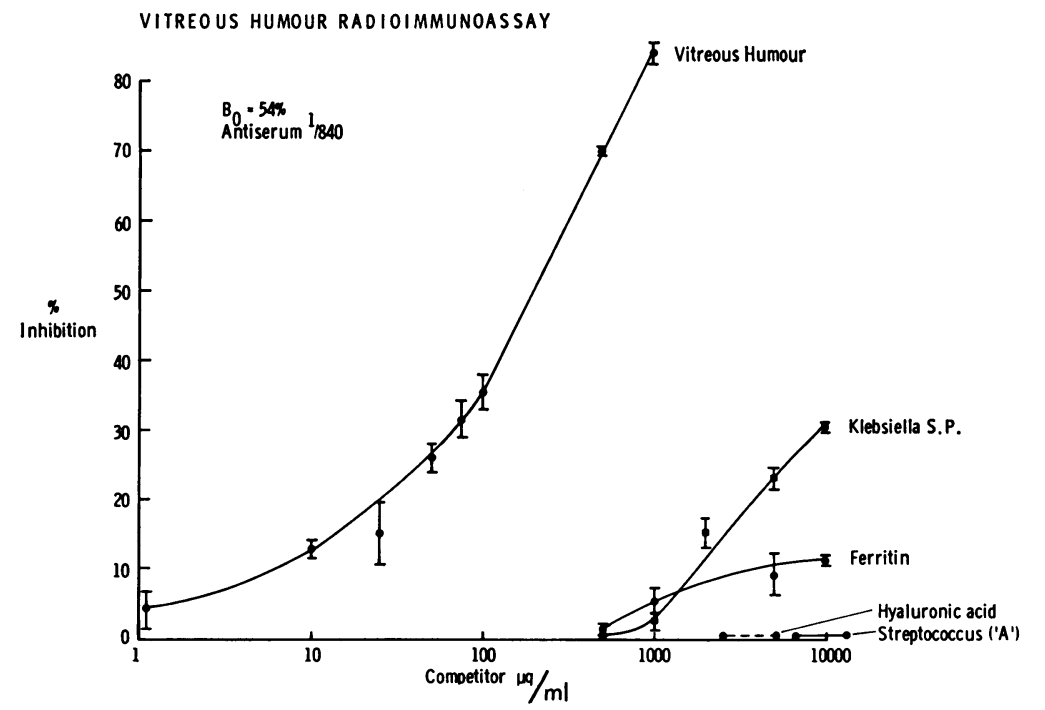

Fig. 2 Inhibition of calf $\mathrm{CVH}-{ }^{125} \mathrm{I}$ tracer binding to rabbit anti-VH-Ig, at a dilution of $1 / 840$, by increasing amounts $(\mu \mathrm{g} / \mathrm{ml})$ of unlabelled vitreous humour, klebsiella sonicate preparation, ferritin, hyaluronic acid, and streptococcus $A$ antigen. Bars represent means \pm standard errors. 
Fig. 3 Inhibition of cow $\mathrm{CVH} \mathrm{C}^{125} \mathrm{I}$ tracer binding to rabbit anti-VH-Ig (A2), at a dilution of $1 / 300$, by increasing amounts $(\mu \mathrm{g} / \mathrm{ml})$ of unlabelled vitreous humour, klebsiella and E. coli sonicate preparations, and ferritin. Bars represent means \pm standard errors.

VITREOUS HUMOUR RADIOIMMUNOASSAY

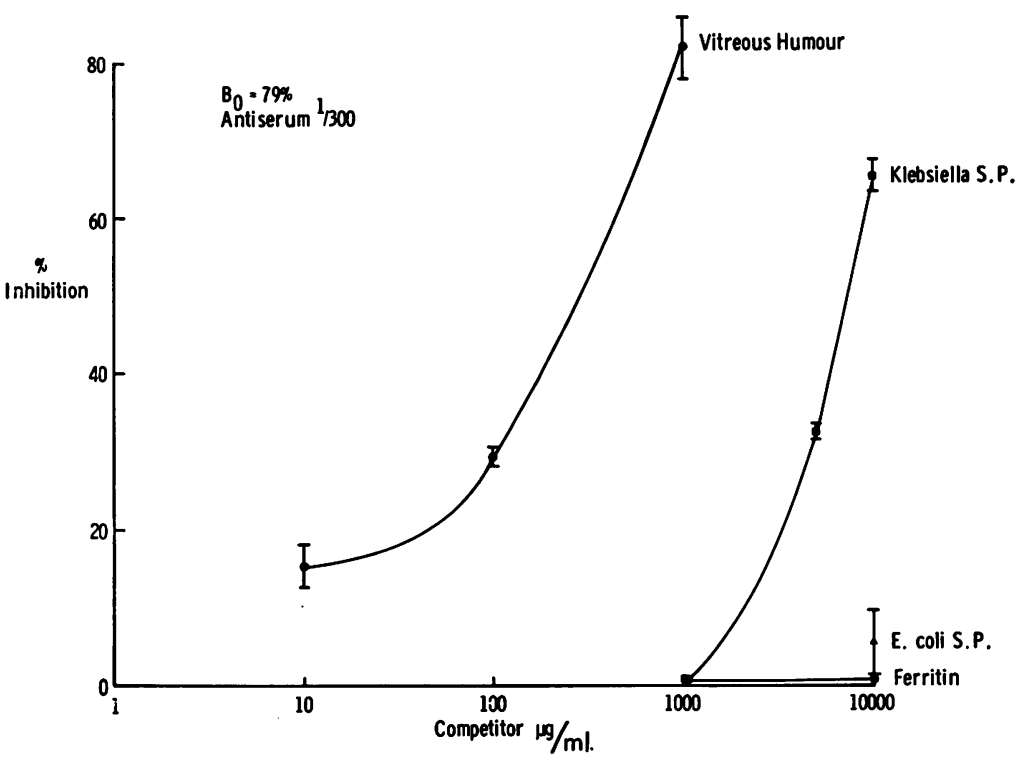

At $10000 \mu \mathrm{g} / \mathrm{ml}$ of competitor, klebsiella extract (KSP) showed $65.5 \%$ inhibition of vitreous humour binding by anti-VH-Ig (A2) at a dilution of $1 / 300$ $\left(B_{0}=79 \%\right)$, while an equal amount of $E$. coli extract produced $4.8 \%$ of inhibition, and ferritin had no effect (Fig. 3).

Another preparation of anti-VH-Ig (A1), at a dilution of $1 / 110\left(B_{0}=47 \%\right)$, showed $100 \%$ inhibition with $10000 \mu \mathrm{g} / \mathrm{ml}$ of klebsiella sonicate preparation (KSP), and this difference is statistically significant when compared with all other competitors $(t=11.76, \mathrm{p}<0.001)$. An equal amount of $E$. coli sonicate preparation showed $28 \%$ inhibition and ferritin $10 \%$. Lower concentrations of competitor again produced correspondingly smaller degrees of inhibition.

\section{Discussion}

Antigenic similarities between vitreous humour and klebsiella micro-organisms were suggested by the studies described in the previous paper, namely,

Fig. 4 Inhibition of cow $C V H-{ }^{125} I$ tracer binding to rabbit anti-VH-Ig (AI), at a dilution of $1 / 110$, by increasing amounts $(\mu \mathrm{g} / \mathrm{ml})$ of unlabelled vitreous humour, klebsiella, and E. coli sonicate preparations and ferritin. Bars represent means \pm standard errors.

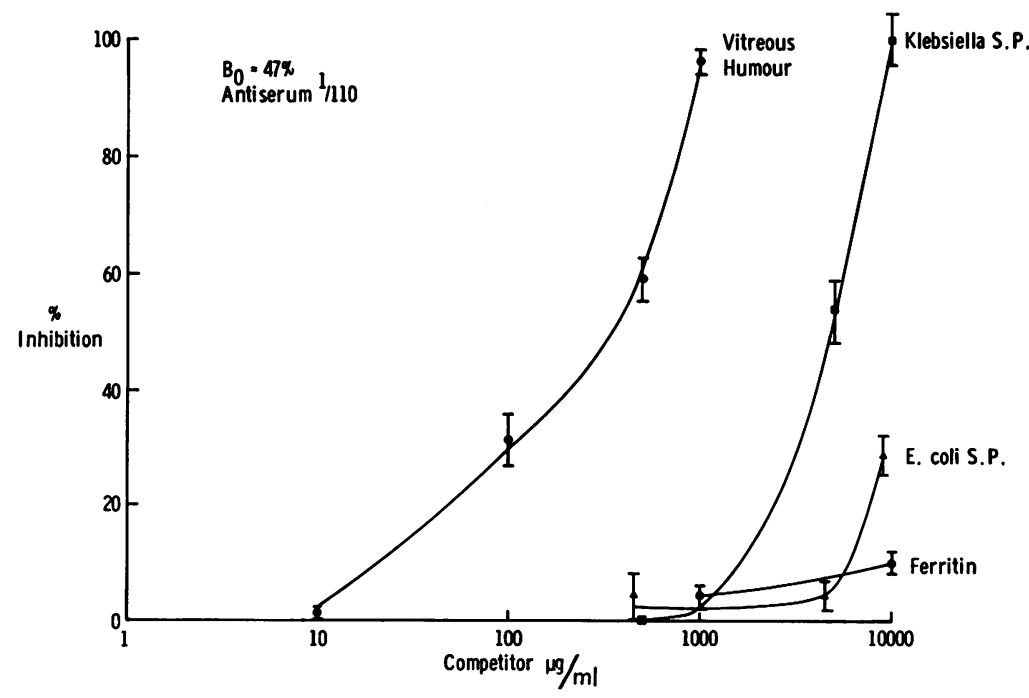


binding studies with labelled vitreous humour. Rabbit antisera raised against klebsiella were found to bind vitreous humour to a greater extent than sera raised against other bacterial or viral antigens. Radioimmunoassay studies described here show that klebsiella antigens directly inhibit the binding of vitreous humour antigen to antivitreous humour antibodies. A similar preparation from another Gram-negative micro-organism, Escherichia coli, showed a lower level of inhibition, while other mammalian antigens, such as ferritin, hyaluronic acid, and bovine haemoglobin showed little or no inhibitory effect. A bacterial preparation from a Gram-positive micro-organism, streptococcal group A antigen, also had no inhibitory effect on the binding of vitreous humour antigen by vitreous humour antiserum. The klebsiella preparation has greater inhibitory effect when cow rather than calf vitreous humour is used in the radioimmunoassays. This lower level of inhibition may either represent differences in vitreous humour composition between young and old animals or could be due to the antiserum raised in the rabbit, which had been immunised with vitreous humour obtained from eyeballs of old cows.

Cross-reactivity in radioimmunoassay systems depends on the $B_{0}$ value, which arises from the relationship between bound and unbound fractions of radiolabelled tracer and affinity of antibodies in the antiserum used in the assay system. Immunochemical studies using haptenic systems have shown that the higher affinity antibodies interact to a greater extent with antigen analogues than lower affinity antibodies isolated from the same serum. ${ }^{12}$ The relationship of the $B_{0}$ value to cross-reactivity is therefore the result of a very complex dynamic equilibrium between antibody affinity, amount of tracer, and the affinity of the competitor for the antibody binding site. At present there are no satisfactory physicochemical models for multisite antigen-antibody systems, while precise measurements of affinity constants for these interactions are lacking. Therefore, the assessment of cross-reactivity in such systems requires caution, and comparisons can be made only between the different competitors. The data presented here consist of comparisons between the homologous antigen, vitreous humour, and a number of heterologous antigens, each having a varying degree of biochemical homogeneity and immunological heterogeneity. The preparation from klebsiella micro-organisms was found to compete for antivitreous humour antibodies, compared to other antigens of similar heterogeneity, and one possible explanation is that klebsiella microorganisms have antigens which resemble some vitreous humour components.
Klebsiella are non-motile, capsulate, Gramnegative bacilli of the family Enterobacteriaceae, frequently found in the lower gastrointestinal tract of man. Investigations into the composition of capsular polysaccharides of klebsiella have demonstrated the presence of glucuronic acid and various monosaccharides such as mannose and galactose, ${ }^{13}$ and a similar polysaccharide composition has been described for vitreous humour. ${ }^{14}$ Lipopolysaccharides extracted from Gram-negative bacteria have been shown to specifically inhibit lymphocytotoxic activity of various HLA antisera, ${ }^{15}$ and it was suggested that lymphocytotoxins evoked by bacterial antigens could affect the host's own tissues. Thus cross-reactive antibodies, produced after bacterial infection with micro-organisms such as klebsiella, which bind to vitreous humour antigens, as suggested by this study, could be involved in the development of anterior uveitis. The acquisition of an enteric flora has been suggested as a possible cause for the development of isohaemagglutinins in neonatal animals, including man, ${ }^{16}$ and thus the appearance of cross-reacting antibodies against other tissues, such as vitreous humour, could also occur after infection of the gastrointestinal tract with Gram-negative micro-organisms.

Antibodies produced after an infection by klebsiella could bind to tissues containing large quantities of cross-reacting material such as vitreous humour and other eye antigens, activate the complement cascade, and produce an inflammatory response. Acute anterior uveitis could be a manifestation of such a process, possibly through the adjuvant effect of some concurrent infection. ${ }^{17}$ In experimental animal models, such as adjuvant arthritis, a systemic disease is produced which is characterised by arthritis of peripheral joints and spinal column, together with a nongranulomatous uveitis. ${ }^{18}$ It has been suggested that adjuvant-induced uveitis is probably the result of an immunological response of the hypersensitivity type to bacterial antigens, ${ }^{19} 20$ and the demonstration of cross-reactivity between klebsiella micro-organisms and vitreous humour in this study is consistent with such a concept.

It is suggested that uveitis in patients with ankylosing spondylitis could be produced by antibodies evoked after gastrointestinal infection by Gram-negative bacteria.

We thank Dr A. C. Boyle and the Arthritis and Rheumatism Council for support. J. W. was in receipt of an SRC studentship.

\section{References}

1 Brewerton DA. HLA-B27 and the inheritance of susceptibility to rheumatic disease. Arthritis Rheum 1976; 19: 656-68. 
2 Woodrow JC. HLA 27 and Reiter's syndrome. Lancet 1973; ii: 671-2.

3 Mapstone R, Woodrow JC. Acute anterior uveitis and HLA-B27. Lancet 1974; i: 681-2.

4 Ebringer RW, Cawdell DR, Cowling P, Ebringer A. Sequential studies in ankylosing spondylitis: association of Klebsiella pneumoniae with active disease. Ann Rheum Dis 1978; 37: 146-51.

5 Ebringer R, Cawdell D, Ebringer A. Klebsiella pneumoniae and acute anterior uveitis in ankylosing spondylitis. $B r$ Med J 1979; i: 383.

6 Eastmond CJ, Willshaw HE, Burgess SEP, Shinebaum R, Cooke EM, Wright V. Frequency of faecal Klebsiella aerogenes in patients with ankylosing spondylitis and controls with respect to individual features of the disease. Ann Rheum Dis 1980; 39: 118-23.

7 Ebringer A, Cowling P, Ngwa Suh N, James DCO, Ebringer RW. Crossreactivity between Klebsiella aerogenes and B27 lymphocyte antigens as an aetiological factor in ankylosing spondylitis. In: Dausset J, Svejgaard A, eds. HLA and Disease. Paris: INSERM, 1976; 58: 27.

8 Welsh J, Avakian $\mathrm{H}$, Cowling $\mathrm{P}$, et al. Ankylosing spondylitis, HLA-B27 and klebsiella. I. Crossreactivity studies with rabbit antisera. $B r J E x$ Pathol 1980; 61: 85-91.

9 Avakian H, Welsh J, Ebringer A, Entwistle CC. Ankylosing spondylitis, HLA-B27 and klebsiella. II. Crossreactivity studies with human tissue typing sera. $\mathrm{Br} J$ Exp Pathol 1980; 61: 92-6.

10 Seager K, Bashir HV, Geczy AF, Edmonds J, De VereTyndall A. Evidence for a specific B27 associated cell surface marker on the lymphocytes of patients with ankylosing spondylitis. Nature 1979; 277: 68-70.

11 Avakian H, Abuknesha R, Welsh J, Ebringer A. Uveitis, vitreous humour, and klebsiella. I. Binding studies with rabbit antisera. $\mathrm{Br} J$ Ophthalmol 1981; 65: 315-22.

12 Exley D, Avakian $\mathrm{H}$. The relationship of specificity to affinity of anti-hapten sera. $J$ Steroid Biochem 1977; 8: 1153-8.

13 Curvall M, Lindberg B, Lonngren J, Nimmich W. Structural studies of the capsular polysacchararide of klebsiella type 28. Carbohydrate Res 1975; 42: 95-105.

14 Buddecke E. Glycoproteins in mammals. In: Gottschalk A, ed. Glycoproteins. Amsterdam: Elsevier, 1972.

15 Hirata AA, McIntyre FC, Terasaki PI, Mittal KK. Crossreactions between human transplantation antigen and bacterial lipopolysaccharides. Transplantation 1973; 15: 441-5.

16 Boyden SV. Natural antibodies and the immune response. Adv Immunol 1966; 5: 1-28.

17 Rahi AHS, Garner A. Immunopathology of the Eye. London: Blackwell, 1976.

18 Pearson CM, Wood FD. Studies of polyarthritis and other lesions induced in rats by injection of mycobacterial adjuvant. Arthritis Rheum 1974; 17: 409-16.

19 Waksman BH, Bullington SJ. Studies of arthritis and other lesions induced in rats by injection of mycobacterial adjuvant. Arch Ophthalmol 1960; 64: 751-62.

20 Rosenbaum JT, McDevitt HO, Guss RB, Egberg PR. Endotoxin induced uveitis in rats as a model for human disease. Nature 1980; 286: 611-3. 